\title{
NOVAS ROTAS, NOVOS VÔOS: A MULHER OCUPANDO ESPAÇO NA EDUCAÇÃO E NO TRABALHO
}

\author{
NEW ROUTES, NEW FLIGHTS: \\ A WOMAN OCUPPYNG AREA IN EDUCATION AND AT WORK
}

Silvia Mara Veronese ${ }^{3}$

\begin{abstract}
Resumo
O objetivo desse texto é discutir sobre as relações sociais constituintes do gênero feminino, enquanto sujeito do corpo social, em sua inserção na formação aeronáutica. Tem como fundamentação as teorizações de Nietzsche e Foucault, em uma pesquisa genealógica focalizando a formação superior para tecnologia aeronáutica, onde a problemática busca esclarecer a causa do aumento de graduadas na aviação civil, área que era tradicionalmente de predomínio masculino. Paradigmas, mercado de trabalho, formação tecnológica e Estado, dispositivos que normalizam habilidades e competências dos sujeitos, organizando a atual sociedade do controle, são discutidos em cooperação com o deslocamento do poder dentro das relações, permitindo a busca de perspectivas para o gênero feminino. O trabalho destaca a excessiva valorização das interpretações verbais e sociais que conduziram à formação dos sujeitos, e o movimento social silencioso que promove a desconstrução de princípios institucionalizados, bem como sua repercussão nas identidades femininas. Aborda também, o movimento individual das mulheres em direção ao mercado de trabalho, passando pela formação superior, tomado como forma de expressão cultural reivindicatória, abrangendo as questões que envolvem as relações de poder entre os gêneros e as relações sociais entre trabalho e educação, que poderão se traduzir na definição de um espaço conquistado.
\end{abstract}

Palavras-chave: Formação superior, aviação, gênero feminino; políticas públicas.

\begin{abstract}
The objective of this text is to argue on the constituent social relations of the feminine gender, while subject of the society, in its insertion in the aeronautical formation. It has as recital the theory of Nietzsche and Foucault, in a genealogical research focusing the superior formation for aeronautical technology, where the problematic search to clarify the cause of the increase of graduated civil aviation, area that was traditionally of masculine predominance. Paradigms, market of work, technological formation and State, devices that normalize abilities and abilities of the citizens, organizing the current society of the control, are argued in cooperation with the displacement of the power inside of the relations, having allowed the search of perspectives for the feminine gender. The work detaches the extreme valuation of the verbal and social interpretations that had lead to the formation of the citizens, and the quiet social movement that promotes the unmake of institutionalized principles, as well as its repercussion in the feminine identities. It also approaches, the individual movement of the women in direction to the work market, passing for the superior formation, taken as form of vindictive cultural expression, enclosing the questions that involve the relations of being able between the sorts and the social relations between work and education that can characterize a conquered space.
\end{abstract}

Keywords: Superior formation, aviation, feminine gender, public politics.

1 Mestre em Educação pela Universidade Tuiuti do Paraná; profissional da área de aviação civil. Email:silveronese@yahoo.com.br. 


\section{INTRODUÇ̃̃̃O}

O objetivo deste trabalho é compreender como as "tecnologias", "normas" e "morais" constituem as relações do gênero feminino, enquanto sujeito de uma sociedade sob a intervenção da ciência e da tecnologia. Particularmente, é um processo que valoriza o ter em detrimento do ser, e a partir desse pressuposto, convenciona-se uma lógica contraditória e ilusória, onde embora o processo de formação superior para tecnologia aeronáutica visa uma idealidade e constitua a possibilidade de transformação de padrões, o resultado é um profissional disciplinado a partir de pressupostos milenares.

Paradigmas sociais, mercado de trabalho e Estado, dispositivos que normalizam habilidades e competências dos sujeitos, organizando a atual sociedade do controle, são discutidos em cooperação com o deslocamento do poder dentro das relações, permitindo a busca de perspectivas para o gênero feminino. O profissional que surge desse processo qualifica uma sensação de mal-estar que permeia a sociedade pós-moderna, demonstrando o sucesso da construção da subjetividade do indivíduo e o fracasso da autodescoberta como sujeito social.

Essa condição de atividade disciplinada que tem ação sobre a limitação da capacidade de invenção da própria subjetividade persiste em apoiar-se nos padrões e no desejo que os símbolos possam representar. $\mathrm{O}$ trabalho destaca a excessiva valorização das características polarizadas que conduziram à formação dos sujeitos ao longo da história e o movimento social que promove a desconstrução ${ }^{2}$ de princípios institucionalizados, bem como sua repercussão nas identidades ${ }^{3}$ femininas. Com base nas articulações teóricas de Nietzsche e Foucault, reflete-se acerca da subjetividade atribuída ao gênero feminino e as novas identidades que estabelece enquanto busca na educação tecnológica apropriar-se de seu espaço social.

Para tanto, assume-se a genealogia ${ }^{4}$ investigativa a fim de revelar a forma de pensar o poder, que permite à educação tecnológica atrair e disciplinar as mulheres, que busca mitigar suas desilusões nessa cultura e a negar a complexidade de seus gestos enquanto ações estratégicas. O movimento feminista é tomado como forma de expressão cultural reivindicatória, restringindo-se nesse trabalho às questões que envolvem as relações de poder entre os gêneros e as relações sociais entre trabalho e educação, que poderão se traduzir na definição de um espaço conquistado.

2 A utilização do termo desconstrução por Foucault não está em um sentido apenas de "desfazer". Para o autor, a desconstrução não é um fim em si mesma, e, sim o conceito çom que ele resume a forma de aprofundar práticas, de rever, refazer o caminho e reconstruir. É a possibilidade de retroceder no contexto histórico que norteia determinado fato, não ao momento de sua gênese, mas de sua emergência e ascendência.

3 A construção de identidades do gênero feminino é resultado do meio em que está inserida, possuindo um compartilhamento de significados culturais, com base ainda, na distinção biológica da mulher.

4 A genealogia de Foucault (1990) é uma desconstrução dos enunciados, relacionados a um momento histórico que representem a gênese ou parte importante da constituição dos saberes, dos discursos e dos domínios do objeto de pesquisa. 


\section{DECOLANDO: COMO SE CONSTRUIU UMA DISCRIMINAÇÃO SUBJETIVA?}

A revolução promovida pelas mulheres vem contestando os tradicionais espaços de atuação masculina. É uma revolução fundamentada no princípio da paciência, institucionalizada como propriedade feminina e forma pela qual se promoveram deslocamentos nos limites sociais milenarmente instituídos. A fim de transpor necessidades econômicas e questões sócio-culturais, o gênero feminino promoveu essa revolução silenciosa e consolidou sua atuação, deslocando e alterando limites que demarcavam as desigualdades entre homens e mulheres.

São sutis mudanças que levam continuamente a diferentes deslocamentos nas relações de poder entre os gêneros. Quando se atenta o olhar a esse movimento, compreende-se a articulação das estratégias do poder que também refletem nos discursos $^{5}$, de maneira objetiva e subjetiva.

Demonstrando pelo curso da história como se constrói e se permuta de acordo com a temporalidade e objetivos sociais, "verdades" tidas como perenes que instituem o questionamento sobre o comportamento feminino. A desconstrução da história das mulheres consiste em uma forma de observar e se mover entre as margens que a formam, descrevendo de maneira contextual seus traços, observando todos os lados que a constituem.

Com base na perspectiva foucaultiana desenvolve-se uma análise conceitual das relações de poder, nas quais está inserido o gênero feminino, em que se caracteriza a essência ética dos sujeitos.

Mudanças que se materializaram quando o movimento feminista ganhou projeção mundial nos anos de 1960, com o início de um movimento social que se tornou marco histórico da atuação da mulher na história. Então, por meio da utilização da tecnologia da comunicação e da educação, demonstraram que na sociedade do controle, a informação ${ }^{6}$ é o diferencial nos movimentos sociais.

Isso porque, muito antes em uma linha do tempo, mais precisamente na Renascença, no Século XVI, poetas, poetisas e filósofos da tradição cristã, entre outros, exaltavam a necessidade de rever os conceitos que determinavam a subordinação da mulher ao homem. No Século XVIII, destacam-se as publicações do Marquês de Condorcet, cientista político e matemático, entre 1787 e 1793, enfatizando a igualdade entre os sexos.

Somente no Século XIX é definido ao movimento social e político das mulheres pelo termo "feminismo", o qual foi originalmente atribuído ao filósofo francês Charles Fourier, autor de "A Emancipação da Mulher".

A questão da identidade feminina como construto social foi suscitado na década

5 Em Foucault (1986) se considera a primeira constituição do discurso como prática social, que se forma a partir das palavras, dos atos e dos objetos, produzindo então, saber e poder.

6 A informação é a "mercadoria circulante" da sociedade contemporânea, onda o biopoder age de forma a promover as necessidades, a capitalizar emoções, desejos e sentimentos, estimulando comportamentos e escolhas, onde se caracteriza a positividade do exercício do poder por meio da informação contemporânea. Em outro momento, Stuart Hall (2000) defende que as mudanças ocorridas na estruturação da sociedade são resultados da rápida circulação da informação, em diferentes momentos e intensidades, nas diferentes regiões do globo. 
de 1940, por Simone de Beauvoir. A autora afirma que: Ninguém nasce mulher: tornase mulher. Nenhum destino biológico, psíquico, econômico define a forma que a fêmea humana assume no seio da sociedade: é o conjunto da civilização que elabora este produto intermediário entre o macho e o castrado que qualificam o feminino. (BEUAVOIR, 1980).

A autora contextualiza uma época de contestações, recusando o destino inflexível traçado a partir das características biológicas dos sexos, herdado das concepções estabelecidas no século XVIII. Este movimento encontrou seu ápice na década de 1960, quando o feminismo constituiu-se definitivamente como movimento social e político.

Em 1963 o psicanalista Robert Stoller apresentou o termo "identidade de gênero", no Congresso Internacional de Psicanálise, em Estocolmo. Baseado no conceito dos sistemas dialéticos, ele formulou o princípio de identidade de gênero a partir da biologia/cultura, de tal modo que sexo estava vinculado à biologia e gênero à cultura.

O termo gênero tornou-se uma ferramenta analítica ${ }^{7}$ e política, conceituação de questionamento fundamental para a proposição das mudanças imperativas à escrita da história com a visibilidade da mulher. As relações de gênero constituem as identidades, como sexo, profissão, etc., que não são destruídas ao longo do tempo, mas alteradas e articuladas, de forma aberta e receptiva, por isso são sempre inacabadas e efêmeras, condicionadas à relação tempo/espaço a que o indivíduo está exposto. As múltiplas identidades que um sujeito possui, são contextualizadas em inúmeras situações e grupos delimitados pelas relações em que está inserido.

Nesta perspectiva, a identidade compreende a conexão entre o pessoal e o privado. São condições de ligação entre o subjetivo e o objetivo, que determinam seu lugar do sujeito na sociedade a partir de sua identidade, com base na condição biológica. São as diferenças biológicas - o sexo - que determinaram desde os primórdios que homens e mulheres possuíam identidades fixas, o que definia a forma de comportamento e a atuação social. É uma forma de poder que define a identidade, delimitando as diferenças, ambas inseridas no corpo social ${ }^{8}$.

Na busca de traçar uma alternativa ao "único lado" apresentado pela história como "verdade institucionalizada" para o poder dos homens sobre as mulheres, Foucault remonta genealogicamente à Grécia Antiga, reiterando que esse discurso moral foi uma prática incorporada pelo Cristianismo. Nesse discurso ocorria uma dessimetria quanto ao comportamento moral determinado para homens e mulheres, pois o autor compreende essa moral como primazia masculina, pois foi pensada, escrita e difundida dos e para os homens, resguardando seus espaços e direitos. Foi por essa moral masculina que se delineou a moral feminina, pois à mulher restou ocupar e estar no espaço onde o homem não estaria, é a teoria patriarcalista ${ }^{9}$. A moral e a religião cristã também se tornaram

7 Segundo Scott (1990), enquanto ferramenta analítica, o gênero agrupa meios de questionar as estruturas do saber que estão postas. Não se trata de fazer surgir uma nova teoria sobre determinado assunto analisado.

8 A noção de população ou corpo social surge na metade do Século XVIII, em relação ao conceito de governamentalidade, na qual além do corpo, que era o foco de dominação do poder, está a família - o espaço do biopolítico, não apenas público. Este novo elemento é um conjunto de processos que visava à humanidade ou uma parte desta, é uma tecnologia do poder, que visa ao corpo múltiplo da sociedade, o qual precisa de cuidados diferenciados.

9 Teoria de definição de dominação masculina, exercida com maior intensidade a partir da Revolução Industrial, em conjunto com a tradição cristã, na qual homens objetivam transcender sua privação dos meios de reprodução da espécie. (SCOTT, 1990). 
dispositivos reguladores do corpo social.

Compreende-se, então, a construção da teorização dialética com base nos binarismos que permeiam a teoria. São pólos opostos que se relacionam dentro de uma lógica invariável de dominação-subordinação, ou seja, estruturas analíticas balizam limites permitidos aos sistemas avocados. Sendo assim, ao abordar sexo/gênero, a construção da atuação feminina é submetida às limitações biológicas e culturais, ou seja, "ser mulher" correspondia a "ser dona de casa" ou atuar em "profissões femininas 10 ", como professora, enfermeira, entre outras.

Compreendem-se, então, como as identidades fixas de homens e mulheres foram delimitadas a partir de diferenças de sexo. O que se questiona e já foi demonstrado como impreciso é que essas diferenças não devem servir como base de organização social e estudos epistemológicos, sendo para tanto necessário buscar uma alternativa razoável à superação dos limites de modelos e padrões.

Essa é a perspectiva exposta até então, de reconhecimento das diferenças biofísicas e de questionamento da imposição das barreiras psicossociais entre os sexos, onde se constituem os gêneros masculino e feminino. A partir de agora se demonstrará como se instituíram as verdades e normas sobre as quais se desenham a moral e a sociedade.

\section{A TECNOLOGIA DA SUBJETIVÇÃO: A IMPOSIÇÃO DA SUBORDINAÇÃO ONDE SÓ EXISTE A DIFERENÇA.}

Com base na teorização classificada como "sistema gênero-ciência", demonstrou-se que a tese naturalizada da inferioridade física e intelectual das mulheres tornou-se uma condição que possibilitava mantê-las, primeiramente, longe da atuação pública e social, a seguir, do mercado de trabalho e, por fim, da academia e da formação tecnológica. Sendo assim, a pesquisa e a ciência, principalmente as exatas e suas derivadas, converteram-se em área predominantemente masculina.

Apontado como misógino paradoxal, Nietzsche reitera em diversos momentos de sua obra sua admiração e desprezo pela mulher. Enquanto reconhece a capacidade de intelectualidade feminina ao afirmar que "as mulheres tem o entendimento", aponta para a necessidade de mantê-las submissas e controladas, reiterando que elas utilizam a "vantagem de ser mulher para se subtrair do trabalho".

Em toda sua obra o autor trata a mulher como tema transversal e chega à "compreensão" da inexistência de capacidade da mulher em relação às ciências por sua relação direta com a responsabilidade reprodutiva, de procriação da humanidade. No Aforismo 137, Nietzsche (2001) afirma que, "Quando uma mulher tem gosto pelas ciências, há geralmente em sua sexualidade alguma coisa que não está em ordem. A esterilidade já predispõe a certa masculinidade do gosto". (p. 88).

$\mathrm{O}$ autor defende a perspectiva feminina da ciência como sendo inferior à sua capacidade reprodutiva; portanto, indesejável e desnecessária para que se dispense ou

10 Essas profissões eram funções que refletiam a extensão das habilidades femininas, de cuidados com a família e com outros, além da educação e trabalhos manuais que não exigissem força física. 
produza conhecimento. Produzir conhecimento pela ciência considera-se, portanto, um atributo masculino. Ou seja, a mulher possui uma "missão" valorosa, que não é a de produzir ciência, mas produzir quem o fará.

Então, a ciência é masculina. Esta constatação é baseada no modelo do sujeito cartesiano de Descartes ${ }^{11}$, que tem como padrão único e central, o homem, branco e europeu. Desenvolve-se, então, em função da neutralidade, da objetividade e do universalismo proposto pelo movimento iluminista. O projeto científico então desenvolvido, centrado na capacidade de racionalização, exprime a condição de supremacia do sexo masculino.

Além desse pressuposto cartesiano, existem ainda na tradição filosófica ocidental outras três diferentes possibilidades, onde estaria o momento histórico em que a sociedade tornou-se predominantemente masculina em suas concepções e organização:

1. A tradição filosófica grega: que se divide em duas origens.

1.1 Aristóteles e sua concepção biológica, que determina as diferenças biológicas como responsáveis pelas características de cada sexo e a inferioridade do corpo feminino;

1.2 A cosmogonia grega e a lenda da caixa de Pandora ${ }^{12}$, que naturalizou o entendimento do quanto a presença feminina pode ser destrutiva, pelo uso de suas qualidades.

2. A tradição judaica: tendo no Antigo Testamento da Bíblia - a Thorá, sua representação da supremacia masculina. Em Gênesis, um Deus criador masculino dá origem à mulher, gerada da costela do homem e mais tarde atribui a Eva a responsabilidade pela perda do Paraíso.

3. A tradição cristã: onde a legitimidade da supremacia masculina é considerada desde a tradição hierárquica da Igreja Católica, reiterada por seus principais pensadores, como Tertuliano, S. Antonio e S. Coriolano.

A base judaica das sagradas escrituras, o Antigo Testamento, é reforçada na religião cristã pelo Novo Testamento, formando o conjunto de Escrituras Sagradas da Tradição Cristã, a Bíblia. A tradição cristã, que em sua origem é judaica, foi disseminada pelo Ocidente em duas fases: Primeiro, pela influência da Igreja Católica, construiu e manteve através dos séculos o princípio da inferioridade e submissão feminina. Após esse período inicial, a Reforma Protestante dividiu os fiéis, mas não modificou os preceitos.

Esses princípios eram profundamente conhecidos por toda tradição judaicocristã, que se utilizou dele para evitar que as mulheres se constituíssem em uma ameaça ao poder masculino, como, por exemplo, impedindo que elas ocupassem funções administrativas, religiosas e de liderança na hierarquia da Igreja. Sendo assim, limitouse às mulheres prestar apenas a formação necessária para administração do lar e educação

11 "Penso, logo existo", o cogito de Descartes que define a essência e a existência do ser como corpo e mente a partir do princípio "pensar".

12 No início dos tempos existiam dois gêneros humanos: mortais e imortais. Em uma disputa entre os deuses, Prometeu presenteia os mortais com fogo. Na tentativa de vingança, Zeus esboça em uma criatura artificial, a constituição da mulher, que passou a possuir características de superficialidade, auto-suficiência e ser capaz de despertar o desejo nos homens - mortais e imortais. A origem do ser mulher chama-se Pandora e portava uma caixa, a qual quando se abriu, disseminou sobre a terra males que a humanidade desconhecia. Essa lenda naturalizou o entendimento do quanto à presença feminina pode ser destrutiva, pelo uso de suas qualidades. 
da família e que pudesse ser controlada pela Igreja e pelo marido.

Para tanto, ao longo da história ocidental, foram consideradas impuras, pecadoras e responsáveis pelas fatalidades da humanidade. Isto posto, fica visível a disseminação em qualquer uma das linhas de influência aqui descritas, que permearam a civilização ocidental.

Mesmo séculos mais tarde, com a Reforma Protestante e suas re-interpretações bíblicas, não se verificaram mudanças nas tradições postas que determinaram as fortes características da dominação do gênero masculino. As religiões classificadas como protestantes apenas transferiram a inferioridade como uma conseqüência do pecado original e não como uma determinação da simples primazia masculina. Ou seja, uma continuidade da tradição judaica.

Nos momentos históricos que a religião teve precedência sobre a ciência, as mulheres que conseguiam o domínio de conhecimentos populares como as parteiras e curandeiras, foram consideradas bruxas. Esta inferioridade e submissão feminina estão diretamente ligadas ao corpo da mulher - apontado pela religião como origem de perversão e perdição, pela capacidade de despertar o desejo carnal.

O corpo feminino, base do determinismo biológico, que carrega também o estigma da incapacidade de desenvolvimento pleno e das características, limitou a mulher à esfera privada. A relação instituída entre o corpo biológico e a identidade social disciplinou a mulher, neutralizando uma conduta social imprópria à ordem social, e promovendo a consumação de sua função procriadora e mantenedora da família e da sociedade.

Na leitura de Perrot (2005), a partir da Revolução Industrial e da estruturação do capitalismo no Século XIX, as mulheres representavam uma força de trabalho atrativa pelo baixo custo. $\mathrm{O}$ discurso ideologista de integração das mulheres à sociedade civil fica restrito às questões do trabalho. Agravada, porém, pelo desenvolvimento do maquinismo, as profissões qualificadas, que necessitam trabalhadores com maior preparo, delimita ainda mais a atuação feminina.

A fundamentação naturalista do século XIX, que organizou as esferas públicas e privadas, identificadas com os sexos, foi, segundo Perrot (2005), a base da organização racional da sociedade capitalista. O discurso de utilidade social através da responsabilidade reprodutora - exclusiva da mulher - a excluiu da cidadania política, com um discurso normativo que formou sua identidade histórica.

O século XX é marcado pelas grandes descobertas da ciência e pelo desenvolvimento tecnológico. Em meio as grandes transformações, duas guerras mundiais deslocam a forma de atuação social e não se alteram os papéis tradicionais dos sexos, e as alastradas mudanças sociais da guerra são falácias. Isso porque existe um refluxo positivista no movimento feminista caracterizado no trabalho feminino empreendido no período da guerra. Ou seja, mulher que trabalha não o faz por si e para si, mas como mãe e esposa que substitui o soldado.

Portanto, os dados e fatos históricos construíram a sociedade capitalista moderna, e submeteram o gênero feminino a uma posição de complementaridade ao gênero masculino. Essa condição tornou a atuação da mulher confusa e indispensável, na divisão e organização do trabalho nas esferas públicas e privadas.

Essa manipulação de características lembra a Nietzsche, quando dispõe que não há fatos, apenas interpretações. Sendo assim, a cada momento histórico cabe uma representação diferenciada sobre as circunstâncias dispostas, que geram diferentes 


\section{CIÊNCIA E FORMAÇÃO: TECNOLOGIAS DE EDUCAÇÃO E SUBJETIVAÇÃO}

Em Foucault (1990) é possível compreender o atual processo educacional como um dispositivo que possui conjuntos e estratégias, aptas a subjetivar, ou seja, formar e/ou produzir sujeitos. Nessa perspectiva compreende-se que o espaço escolar, além de disciplinar os corpos, domestica as vontades, organiza e dispõe as ciências como instrumento do poder e do saber.

O processo educacional atual promove a construção de sujeitos a partir de ações externas, preparando os indivíduos com o objetivo de destiná-los a participar da máquina social de produção e reprodução. Por outro lado, pela perspectiva foucaultiana ${ }^{13}$, que é uma continuidade do pensamento de Nietzsche, a educação é concebida como um processo de construção livre de si, uma técnica contínua de subjetivação, decorrentes das relações de poder, de saber e jogos de verdade. A escola possui a responsabilidade de capacitar o indivíduo a produzir sua subjetividade de forma livre, e não condicionada a ações externas, como se realiza atualmente.

É possível entender então que o sujeito é mais livre do que imagina, e a capacidade de transgredir perspectivas naturalizadas está no processo educacional, em que o sujeito recebe ferramentas para desenvolver sua criatividade. A criatividade possibilita ao sujeito aptidão de questionar constantemente, além de formar uma essência ética ${ }^{14}$ condizente com sua conduta moral.

Essa afirmativa tem por base o perspectivismo de Nietzsche, que criticou a consolidação da ciência como uma verdade imutável, pois a compreendia como "precursora e criação do conhecimento, que por sua vez constitui-se em uma representação da vontade de potência", ou seja, está ancorada na pluralidade de possibilidades e no dinamismo da construção do saber. Portanto, a ciência enquanto construção neutra e objetiva foi criticada por Nietzsche, que não assume, porém, a subjetividade como oposição, o que caracterizaria apenas uma inversão dos valores.

A proposição é de transmutação, de uma superação da moralidade para a transvaloração ${ }^{15}$ dos novos valores, a superação da fraqueza pela afirmação da vida, da construção do conhecimento a partir da razão autosuficiente. O saber na perspectiva da interpretação considera o ponto de vista de quem o produz, pois este reflete a

13 Veiga Neto (2000) considera, em diversos momentos, o desenvolvimento do pensamento foucaultiano que, após a passagem pela Escola de Frankfout, denota sua inclinação para a continuidade de seus estudos com base na teorização nietzschiniana.

14 Foucault (2004) considera que essência ética do sujeito está na sua capacidade de viver em consonância com o que declara, em qualquer situação. Essa capacidade se desenvolve a partir de sua relação educacional consigo e com os outros e demonstra o valor e o rigor no cuidado de si e dos outros, o que denotava sua estética da existência.

15 Segundo Nietzsche (2001), é a capacidade de transvalorar, onde o homem não apenas revê seus valores, mas institui novos e em constante transformação e, ainda, consegue estabelecer sua posse na relação da vontade de poder e tempo. Percebe-se com a realização da pesquisa que horizonte pretendido pelas mulheres é essa condição proposta pelo autor de novos valores e constante mutação em relação ao poder. 
multiplicidade de vontades hierarquicamente organizadas, expandidas na potência da vida.

O ser que pensa, sente e quer é autosuficiente em sua vontade de potência, refletindo em sua construção científica a liberalidade que assumiu; assim, o saber se torna em uma descoberta da vida, a própria essência do sujeito. Essa interpretação das condições representadas no conhecimento não reflete na unicidade do sujeito, mas na sua capacidade de multiplicar as condições de construir o conhecimento, a partir do dinamismo das relações de poder que exerce e sob as quais está exposto.

Esse conceito vai ao encontro do pensamento de Foucault, que compreende o processo educacional promovendo no sujeito a criatividade. Essa condição possibilita ao sujeito aptidão de questionar constantemente, além de formar uma essência ética condizente com sua conduta moral. $\mathrm{O}$ autor concebe que a escola não pode ser o espaço de respostas às demandas imediatas do mercado, onde se "disciplinam aptidões e capacidades", onde prevalece o aprendizado pela produtividade e não a formação de novas condições de subjetividade.

Apesar dessa proposição, a educação e a tecnologia passaram a ser a busca por uma verdade útil, pois não são apenas uma experiência ou algo que se possa aprender, mas sim uma perspectiva do mundo, que necessita de condições que possibilitem a existência em uma conjuntura social. Portanto, o sujeito e o meio como ponto de partida precisam ser considerados uma condição possível para o surgimento e a existência da tecnologia, por meio da educação na forma material de interpretação da realidade, apresentada como um problema.

\section{TETO DE VIDRO EM CÉU DE BRIGADEIRO: A DISCRIMINAÇÃO}

Os deslocamentos do poder nas relações são compreensíveis por meio dos discursos disciplinadores, do biopoder e da atuação social das profissionais da aviação brasileira. A possibilidade de compreender a forma de deslocamento do poder nas relações fundamenta-se com a realização de uma desconstrução histórica.

O surgimento dos cursos de formação superior na área de aviação oportunizou às mulheres uma outra forma de ingressarem no mercado de trabalho da aviação, realizando sua formação nos cursos superiores, bacharelados ou tecnológicos. As primeiras mulheres com a formação superior em aviação - civil e militar entram para a história como parte de um grupo seleto de profissionais. Com formação técnica e humanística que o ensino superior proporciona, atuam em uma área de extenso desenvolvimento tecnológico e comercial.

$\mathrm{Na}$ medida em que a mulher ocupou o mercado de trabalho na aviação ${ }^{16}$, inserida em um contexto sócioeducacional do paradigma masculino, permitiu o surgimento de pesquisas, buscando compreender sua atuação, a partir da formação superior da aviação brasileira.

16 Segundo Veronese (2007), a história da mulher na aviação tem início com a cubana Aída Costa, que em 1903 pilotou um dos balões de Santos Dumont em Paris. Guarda personagens importantes, como a engenheira E.Lilian Todd e a russa Valentina Tereshkova, respectivamente a primeira engenheira aeronáutica e a cosmonauta da história da aviação. No Brasil, na década de 1920, Thereza de Marzo e Anésia Pinheiro Machado e, em 2004, a cadete da Força Aérea Brasileira (FAB) Fernanda Görtz, recebem a referência de quem fez história ocupando os céus. 
Pesquisar esse processo implica, então, buscar a compreensão de como são constituídas as capilaridades do poder através das relações sociais que envolvem a área tecnológica da aviação civil. Ainda, explorar a movimentação do poder naturalizado ${ }^{17} \mathrm{e}$ institucionalizado pelo discurso, tomando como objeto o estudo do gênero feminino enquanto tem sua formação para atuação na aviação civil, uma área legitimada como masculina.

As atuações profissionais na aviação estão incluídas em outras diversas situações que envolvem esse processo de conquista contínua de espaços de trabalho tradicionalmente masculinos pelo gênero feminino, e que acabam se tornando parte da sociedade globalizada do Século XXI.

Ao considerar-se que o sujeito é um conjunto de diversas identidades, as profissões são elementos de formação dessas identidades e, também, alimentadoras de paradigmas. São consideradas extensões dos limites nos universos feminino e masculino, enquanto considerados pólos binários de oposições permanentes.

Nessa perspectiva, os homens e mulheres têm sua atuação demarcada pelas supostas características do sexo, tendo uma identidade fixa caracterizada como social ou sexual. Como conseqüência dessas identidades imutáveis, conduz à formação profissional dentro de um determinado modelo ou padrão.

Esse padrão de atuação profissional é relativo a profissões com características de educação e cuidados, uma extensão do que se considerava o "universo feminino". Ao romper os paradigmas da identidade única - social ou sexual, transpõem os limites dos discursos disciplinadores.

Essa ação é possível a partir de uma perspectiva ética de relação consigo, das tecnologias do eu. Ou seja, de compreender as limitações dos modelos sociais que balizam às relações do e com o gênero feminino. Ao compreender o funcionamento desses modelos, transpõe paradigmas, como a procura pela formação no ensino superior da aviação civil.

Porém, os mesmos paradigmas que antes balizavam as formações profissionais, podem se transferir para manter as estruturas hierárquicas no mercado, que sustentam as disparidades entre os gêneros. Esse processo acontece tornando como pretensamente naturais às desigualdades entre os gêneros masculino e feminino, no que se refere à ocupação de cargos, funções e remuneração salarial.

A primeira vem a ser da segregação hierárquica, na qual dispõem as posições secundárias, quando se verifica o cenário da atuação feminina nesta amostra, suas posições no mercado de trabalho. A segunda é a noção do "teto de vidro", a qual consiste na existência de uma suposta barreira invisível, a qual impede as mulheres de atingirem o topo das organizações; nesse caso, das empresas de aviação civil.

No corpo social, o status da profissão na área aeronáutica é diretamente ligado às características definidas ao longo da história como peculiares aos homens, como raciocínio lógico e capacidade de localização espacial. Pelo padrão constituído para esta profissão, é mantida a hegemonia masculina na pirâmide social, construída a partir da

17 Em Foucault (1990), e pode compreender que a "naturalização" de normas e regras acontece pela institucionalização do enunciado do discurso dominante, estabelecendo comportamentos, ações e relações pressupostos e desejáveis. 
escola, de forma a contribuir com o disciplinamento do sujeito para o padrão que o corpo social aceita como "normal".

Compreendidos quais padrões consensuais definem profissionalismo da aviação, as questões a serem compreendidas giram em torno de temas de, como se definiram essas normalizações, o que representam? Seriam consensos, os fatores que determinaram a submissão do gênero feminino, como a cultura grega e a tradição judaico-cristã? Então, a aceitação desses padrões, ou como chegou-s a eles e seria a simples imposição de uma verdade da moral escrita "pelo e para os homens".

Atendendo a uma das demandas desse mercado de aviação, a universidade recebe uma função que Foucault compreende por seletiva, não apenas de sujeitos, mas de saberes também. É uma atribuição que caracteriza e normaliza o processo educacional brasileiro na direção da formação profissional tecnológica - direcionada ao mercado - em detrimento da formação mais humanista, característica de cursos da área de ciências humanas e sociais.

Ainda, a escola não pode ser apenas um espaço de reprodução de saberes, escolhidos e hierarquizados, mas pode e deve ser um instrumento de constituição do conceito nietzscheniano "além-homem ${ }^{18}$ ", ou da transvaloração, em que a educação é um dos instrumentos necessários para esta autosuperação e autotransformação, pois tem a condição de intervir individualmente, enquanto também em grupo.

Isso porque, segundo Louro (2004), a escola é ainda um dispositivo que fixa as subjetividades atribuídas ao gênero feminino no decorrer da história, multiplicando o exercício do poder masculino hegemônico sobre as mulheres. Ou seja, apesar da formação diferenciada e da aceitação positiva no mercado aeronáutico, as mulheres ainda estão condicionadas a escalões secundários, sem condição de tomada de decisão nas organizações. Esse cenário é característico à sujeição feminina ao exercício do poder masculino.

O que se pode compreender então, é que a escola participou desse processo como instrumento de inversão da subjetivação. Assim, objetivando-se o ser ou a sujeição do indivíduo aos padrões vigentes em determinado momento histórico, relegava-se ao segundo plano o saber, como condição de construção e formação intelectual do sujeito. A mulher chega ao mercado de trabalho convenientemente normalizado, sem questionar verdades postas que a relegam ao segundo escalão da aviação.

A subjetividade no trato do gênero feminino diz respeito ao que as ações e políticas públicas para o ensino superior tecnológico e mercado de trabalho da aviação não explicitam, mas incluem. As mulheres nunca foram proibidas de freqüentar o ensino tecnológico ou as áreas de exatas. O gênero feminino era sim influenciado por discursos e normas morais a freqüentar os cursos que relacionavam o aperfeiçoamento de competências com suas habilidades "naturalmente" femininas, de cuidados, educação e higiene.

Dessa forma, os elementos que geram a substância ética acabam por determinar a forma pela qual o indivíduo se torna parte de sua conduta moral, a partir de suas práticas

18 Esse além-homem é também compreendido como uma nova subjetividade, uma nova estética da existência, enquanto modo de pensar e agir. Segundo a perspectiva foucaultiana, as novas subjetividades são conseqüência, pela lógica paraconsistente, das relações que se estabelecem consigo e com os outros, quando se questionam princípios e padrões estabelecidos a priori. 
cotidianas. Sendo assim, o exercício diário da formação do sujeito-mulher, enquanto profissional da aviação civil, foi pesquisada, questionada e compreendida nesse trabalho segundo uma metodologia que atrela a tecnologia aeronáutica e a compreensão da atuação das estratégias de poder nas relações entre os gêneros masculino e feminino.

A presença da mulher na formação e no mercado de trabalho da área tecnológica ganhou contornos históricos com as pesquisas realizadas sobre historicidade de gênero, levando às reflexões sobre a possibilidade da re-escrita da história dos sujeitos. Essa historicidade gerou na contemporaneidade um momento de transição, em que os princípios, modelos e padrões até então admitidos e repetidos desde Platão, passando pela Revolução Industrial, já não mais contempla as múltiplas identidades do sujeito.

As evidências sugeriram ainda que as regras e as normas sociais moldaram os padrões e modelos do comportamento do gênero feminino, conforme a desconstrução teórica realizada sobre as questões da sua identidade e da construção e subjetivação do "eu”, a partir de tecnologias do poder.

Por identificação pessoal da autora, a pesquisa ${ }^{19}$ limitou a aviação: um espaço tradicionalmente masculino, em que atuam profissionais com características de raciocínio lógico e analítico, definidas ao longo da história como peculiares aos homens. Espaço que começa agora a ser paulatinamente ocupado também pelas mulheres, que encontram nessa área um novo ponto de inserção e de projeção social.

O que era uma verdade, instituída e naturalizada como parte das ciências que delimitaram o campo de atuação entre homens e mulheres, está sendo na contemporaneidade não apenas questionada, como também, segundo Foucault, desconstruída para se reconstruir em novo cenário e através de novos desafios.

Como forma de delimitar fatores que caracterizassem as estratégias de poder dentro das relações, foi realizada pesquisa com envio de questionários às egressas e estudantes dos cursos de Ciências Aeronáuticas em duas universidades da Região Sul do Brasil, bem como se realizou a análise do projeto pedagógico ${ }^{20}$ dos cursos. O pressuposto adotado para o balizamento das análises, além do paradoxo anteriormente exposto, foi à necessidade da atuação profissional da mulher na área de tecnologia aeronáutica.

Constatou-se no projeto pedagógico dos cursos de Ciências Aeronáuticas da Universidade Tuiuti Paranense, verificam-se que o objetivo dos cursos é formar profissionais com fundamentos de "raciocínio lógico e quantitativo ${ }^{21}$ " e ministrar aos futuros profissionais saberes específicos a respeito da Aviação Civil. É uma formação de nível superior intencionalmente voltado à área burocrática da operação de aviação civil, disponibilizando ao mercado aeronáutico os profissionais normalizados a partir de um

19 A pesquisa relatada foi tema de dissertação, na qual estudantes e egressas das Faculdades de Ciências Aeronáuticas da Universidade Tuiuti Paranaense á e Pontifícia Universidade Católica de Porto Alegre, que compuseram uma amostra de 23 questionários de múltipla escolha respondidos.

20 A análise realizada nos projetos pedagógicos dos cursos de Ciências Aeronáuticas da UTP e PUC primaram por uma metodologia que veio de encontro à intenção da hipercrítica, que não parte de uma perspectiva considerada como pressuposto do processo educacional. É uma análise no objeto de estudo, que aqui compreende uma conjuntura entre sujeito/objeto, entre a busca pela formação no ensino superior para aviação e o gênero feminino.

21 Expressão que consta na organização curricular para formação deste profissional, disponível em http://www.utp.br/cursos/tecnologia/TGAC.asp. Foucault (1996), Louro (2004) e Silva (2002), percorrem os caminhos da padronização de currículos, saberes e sujeitos, na função de sujeição e subjetivação que impõe à universidade. 
modelo cartesiano adequado para o administrador de empresa aérea.

Assim como o profissional da aviação não o é de forma "natural" e sim constituído ao longo do tempo, assim também o é "ser" mulher; ou seja, esse sujeito é uma composição de identidades que formam um profissional da área tecnológica aeronáutica, pertencente ao sexo feminino. O desenvolvimento dessa pesquisa permitiu visualizar a ciência através de sua relação com a subjetividade que predispõem seus elementos discursivos e não-discursivos, suas práticas e rupturas através do enunciado como formas de discriminação.

A pesquisa demonstrou ainda, segundo a Agência Nacional de Aviação Civil, que existem hoje 678 mulheres profissionais da aviação ${ }^{22}$ atuando em diferentes categorias aeronáuticas. Destas, cerca de 30 são pilotos e co-pilotos atuando em empresas de grande porte, ou linha aérea. Na área militar, a FAB ofereceu 20 vagas para formação das primeiras pilotas em 2003, onde concorreram 3.200 candidatas. Com base nos dados obtidos e na verificação da continuidade do modelo mercadológico que contempla a preferência na contratação de profissionais com perfil "masculino", verificou-se que o padrão não mudou, e, sim, se alteraram os sujeitos que atuam nessa área; ou seja, houve apenas uma movimentação das relações de poder na aviação.

Com base nessa constatação, exprime-se um paradoxo na análise: Por um lado, os fatores que possam ter determinado o aumento da procura pela formação superior na aviação civil refletem o sujeitamento, o comportamento que a sociedade pretendia como conveniente para as mulheres. Por outro, considera também uma forma de transgressão dos padrões, os quais há muito tempo determinaram os locais e as profissões em que as mulheres poderiam desenvolver sua atuação profissional.

Esse paradoxo sugere que, na contemporaneidade, se a mulher fala e é falada, é porque reagiu de forma diferente ao exercício do poder masculino. Essa reação ou confronto, porém, não aconteceu a partir do exercício do poder que reprime e coage, mas do que suscita, provoca, instiga, estimula e produz. Ou seja, não é na forma em que a mulher investe contra o homem que promove sua visualização, mas na forma que fala e age, como se constitui enquanto sujeito.

Esses pressupostos fundamentam as relações de poder no sentido ascendente que Foucault compreende e descreve. O mercado demanda, sim, diferentes processos de formação por parte das universidades; por outro lado, os sujeitos também buscam adentrar determinado mercado de trabalho, necessitando para tanto a formação profissional. É o que Foucault entende pela capilaridade do poder, não apenas de cima para baixo (mercado), mas principalmente de baixo para cima (sujeito).

Quando delimitadas as estratégias de poder que atuam nos fatores, verifica-se que:

1. A busca por formação em áreas diferenciadas para atuação profissional, onde possam ser reconhecidas pela sua capacidade ou pioneirismo, ou seja, a mulher, estimulada à produção de novos comportamentos, promove o surgimento de outras identidades que a instituem como sujeito social.

2. A tentativa de que sua formação possa ser recompensada financeiramente no

22 Profissionais da aviação caracterizados nesse item são aqueles que atuam, entre outras funções, como piloto e mecânico de aeronave, categorias que requerem registro da ANAC para atuação profissional. 
mercado de trabalho, em áreas adversas às "profissões femininas" portanto, o mercado estimula e instiga a mulher a desenvolver sua capacidade criativa e produtiva no mercado de trabalho, após sua formação.

Assim, as mulheres, conduzidas por essas estratégias presentes nas relações de poder, passam a buscar na área aeronáutica outros meios de posicionarem e serem reconhecidas pelo mercado, como é o caso do ensino tecnológico. Conscientes de suas responsabilidades, não apenas pela utilização e emprego, como principalmente pela constituição e pesquisa dos processos tecnológicos, a mulher se faz presente no desenvolvimento mercadológico que acaba por induzir a adoção de novos padrões culturais.

Dessa forma, o ensino tecnológico torna-se parte do processo de socialização e desenvolvimento do sujeito, enquanto forma de sua preparação e formação para o mercado de trabalho, atendendo ainda às suas necessidades profissionais de subsistência, efetivando o desenvolvimento de suas habilidades e aptidões. Essas competências aprimoradas no sujeito são as necessárias para sua atuação profissional frente à tecnologia e não as que supostamente o indivíduo possua.

A formação tecnológica dos sujeitos é considerada então, um processo imprescindível para o desenvolvimento, a eqüidade, o crescimento e a inclusão, pois o processo tecnológico requer, sucessivamente, níveis cada vez mais elevados de educação e de formação.

Portanto, a educação torna-se parte do processo de socialização do desenvolvimento tecnológico. Porém, o que tem ocorrido no processo educacional tecnológico é a simples transmissão de conhecimentos e informações, sem a formação do saber, ou seja, sem que haja a reflexão sobre a condição do sujeito na integração tecnológica e social.

Esse processo acentua as disputas sociais e, principalmente, as relações entre os gêneros masculino e feminino, e diminui a disposição dos sujeitos a promoverem o seu desenvolvimento, acima das suas diferenças. Uma vez que a aceitação dessas diferenças é a característica precípua da globalização e da multiculturalidade, que se traduz em qualquer processo que limite ou interfira na educação integrada, acentuando ainda mais as distinções sociais e de gênero.

A educação tecnológica, como parte da integração do indivíduo na sociedade, pode proporcionar ao gênero feminino a possibilidade de alcançar a condição plena de cidadania, o que é uma das demandas do movimento feminista. A integração social das mulheres está diretamente atrelada à consolidação do sistema democrático, na garantia pelo Estado dos direitos básicos para seu desenvolvimento como sujeito político. Montesquieu define que a condição democrática da sociedade está atrelada à liberdade das mulheres enquanto sujeito social atuante.

Assim, encontra-se a educação superior em meio a essa discussão: considerada a única instituição capaz de desenvolver condições para que o indivíduo se constitua enquanto sujeito proporcionando o acesso ao conhecimento e ao saber. Por outro lado é também responsável pelo aumento da divisão social, por não ter alcançado êxito na função de constituir a governamentalidade nos sujeitos.

A universidade possui então, além de sua determinação de selecionar saberes, disciplinar indivíduos e capacitar a biopolítica, repetindo o modelo social onde está inserida, a aspiração de proporcionar condições diferenciadas de governamentalidade para o sujeito, nas relações que este institui consigo e com os quais se relaciona. 
E por repetir o padrão da sociedade globalizada, da normalização, a universidade também se constitui de forma paradoxal e se caracteriza por estar em constante evolução, transformação, visto que a norma, na contemporaneidade, não é definitiva. Portanto, ao contrário da sociedade disciplinar, que apenas moldava subjetividades, a sociedade da normalização forma continuamente, atualizando identidade e elementos constituintes do sujeito; é o conceito da fragmentação social.

O princípio da fragmentação aplicada ao trabalho e ao mercado exigiu assim do capital, mais que o controle do mercado consumidor de produtos. Controlar o centro produtor de ciência passou a ser essencial na articulação e mudanças demandadas pela globalização. Sendo assim, a universidade tornou-se também um centro mercantilista, onde o próprio conhecimento é uma mercadoria de grande procura.

Portanto, o grande desafio da educação tecnológica é propiciar condições de formação integral do sujeito, com capacidade de intervenção social, não apenas como profissional atuante da tecnologia. Esse desafio justifica o princípio da transformação social e aprimoramento do sujeito, a partir da técnica e da ciência: é o conceito da tecnologia em sua amplitude.

\section{REFERÊNCIAS}

BEAUVOIR, Simone de. O segundo sexo: a experiência vivida. Rio de Janeiro: Nova Fronteira, 1980.

CARVALHO, Marilia Gomes de. Tecnologia, desenvolvimento social e educação tecnológica. Educação \& Tecnologia, 1. Curitiba: CEFET-PR, 2003.

CASTELLS, Manuel. Sociedade em rede - A era da informação, economia sociedade e cultura. 4 ed. São Paulo: Paz e Terra, 1999.

CHASSOT, Áttico. A ciência é masculina? É, sim senhora. 2 ed. São Leopoldo: Unisinos, 2006.

FOUCAULT, Michel. História da sexualidade. Vol 1: A vontade de saber. 11 ed. Rio de Janeiro: Graal, 1988.

FOUCAULT, Michel. Microfisica do poder - 9 ed. Rio de Janeiro: Graal, 1990.

FOUCAULT, Michel. Tecnologias del Yo y otros textos afines. Barcelona: Paidós Ibérica, 1991.

FOUCAULT, Michel. Ética, politica e sexualidade. Vol. V. Rio de Janeiro: Forense Universitária, 2004. (Ditos \& Escritos).

FOUCAULT, Michel. A Hermenêutica do Sujeito. 2 ed. São Paulo: Martins Fontes, 2006.

NIETZSCHE, Friederich. Humano, demasiado humano. São Paulo: Escala, 2006.

PERROT, Michele. As mulheres ou os silêncios da história. Bauru: EDUSC, 2005.

VEIGA-NETO, Alfredo. Educação e governantalidade neoliberal: novos dispositivos, novas subjetividades. IN: BRANCO, Guilherme C. \& PORTOCARRERO, Vera. Retratos de Foucault. Rio de Janeiro: Nau, 2000.

VERONESE, Silvia M. Novas rotas, novos vôos: a mulher ocupando espaço na educação e no trabalho. Dissertação. Curitiba: UTP, 2007.

\section{BIBLIOGRAFIA}

AVIAÇÃO. Cursos de Graduação. Disponível em:

http://www.educacaosuperior.inep.gov.br/funcional/lista_cursos.asp. Acesso em: 02 abr. 2007.

BRASIL, Lei Federal n ${ }^{\circ} 8.948$, de 08 de dezembro de 1994. Dispõe sobre a instituição do Sistema Nacional de Educação Tecnológica. Diário Oficial da República Federativa do Brasil, Brasília, n. 233, p. 18882, 09 dez. 1994. Seção 1, pt. 1.

BRASIL, Lei Federal n 9.394, de 20 de novembro de 1996. Estabelece as Diretrizes e Bases da 
Educação Nacional. Diário Oficial da República Federativa do Brasil, Brasília, n. 248, p. 27839, 23 dez. 1996. Seção 1, pt. 1.

BRASIL, Parecer CNE/CES n 436, de 04 de abril de 2001. Analisa os Cursos Superiores de Tecnologia no tocante à Formação de Tecnólogos. Diário Oficial da República Federativa do Brasil, Brasília. p. 67, 06 abr. 2001. Seção 1E.

BRASIL, Resolução CNE/CP n ${ }^{\circ}$ 03, de 23 de dezembro de 2002. Institui as Diretrizes Curriculares Nacionais Gerais para a organização e o funcionamento dos cursos superiores de tecnologia. Diário Oficial da República Federativa do Brasil, Brasília, p. 162, 23 dez. 2002. Seção 1, pt. 1.

BRASIL, Presidência da República. Secretaria Especial de Políticas para as Mulheres. Plano Nacional de Políticas para as Mulheres. Brasília, 2004.

CHASSOT, Áttico. Educação ConSciência. Santa Cruz do Sul: EDUNISC, 2003.

DEMO, Pedro. Politicidade, razão humana. Campinas: Papirus, 2002.

FOUCAULT, Michel. A ordem do discurso. Collége de France. Éditions Gallimard, 1971. Disponível em: http://www.geocities.com/bernardorieux/foucault/textos.htm. Acesso em: 20 Maio 2005.

FOUCAULT, Michel. História da sexualidade. Vol 3: o cuidado de si. Rio de Janeiro: Graal, 1995. FOUCAULT, Michel. História da sexualidade. Vol 2:O uso dos prazeres. 8 ed. Rio de Janeiro: Graal, 1998.

FOUCAULT, Michel. As palavras e as coisas. 8 ed. São Paulo: Martins-Fontes, 1999.

FOUCAULT, Michel. Em defesa da sociedade: curso no Collège de France (1975 - 1976). São Paulo: Martins Fontes, 1999.

FOUCAULT, Michel. Vigiar e punir: história da violência nas prisões. 2 ed. Petrópolis: Vozes, 2001.

FOUCAULT, Michel. Estratégia poder - Saber. Vol. IV. Rio de Janeiro: Forense, 2003. (Ditos \& Escritos).

FOUCAULT, Michel. Arqueologia das ciências e história dos sistemas de pensamento. Vol. II. 2 ed. Rio de Janeiro: Forense Universitária, 2005. (Ditos \& Escritos).

FUNDAÇÃO Carlos Chagas. Banco de dados sobre o trabalho da Mulher. Disponível em: http://www.fcc.org.br/mulher/index.html. Acesso em: 19 ago. 2006.

HARAWAY, Donna. Gênero para um dicionário marxista: a política sexual de uma palavra. IN: PONTES, Heloisa (org.). Cadernos Pagu - Revista semestral do Núcleo de Estudos de Gênero. Campinas: UNICAMP, Janeiro / Julho, n. 22, 2004, p. 201-246.

HARAWAY, Donna. Ciência, tecnologia e feminismo-socialista no final do século XX. IN: SILVA, Tomaz Tadeu da (org.). Antropologia do ciborgue - as vertigens do pós-humano. Belo Horizonte: Autentica, 2000, p. 41-129.

HIRATA, Helena. Tecnologia, formação profissional e relações do gênero no trabalho. Revista Educação \& Tecnologia. Curitiba: CEFET, Vol 6, mai, 2003, p. 144-156.

HOBSBAWM, Eric J. Mundos do trabalho: Novos estudos sobre História operária. 4 ed. Rio de Janeiro: Paz e Terra, 2000.

KUHN, Thomaz S. A estrutura das revoluções científicas. 9 ed. São Paulo: Perspectiva, 2005.

LIMA FILHO, Domingos L. Breve ensaio sobre as virtudes da virtualidade. IN: QUELUZ, Gilson L. et alii. Tecnologia e Sociedade: (Im) possibilidades. Curitiba: Torre de Papel, 2001, p. 13-31.

LOURO, Guacira L. Mulheres na sala de aula. IN: DEL PRIORE, Mari. (org.). História das mulheres no Brasil. 7 ed. São Paulo: Contexto, 2004.

MIRANDA, Angela L. Uma análise filosófica sobre as dimensões ontológica, epistemológica e axiológica da tecnologia moderna. 161 f. Dissertação de mestrado - Dissertação de Mestrado em Tecnologia - Programa de Pós-Graduação em Tecnologia, Universidade Tecnológica Federal do Paraná, 2002.

NIETZSCHE, Friederich. A genealogia da moral. 20 ed. São Paulo: Escala, 2001.

NIETZSCHE, Friederich. Além do bem e do mal: prelúdio de uma filosofia do futuro. 20 ed. São Paulo: Escala, 2001.

NIETZSCHE, Friederich. Crepúsculo dos ídolos: ou como filosofar a marteladas. São Paulo: Escala, 2004.

NIETZSCHE, Friederich. $O$ anticristo: ensaio de crítica do cristianismo. São Paulo: Escala, 2004. 
NIETZSCHE, Friederich. A gaia ciência. São Paulo: Escala, 2006.

RAGO, Margareth. Foucault e as artes de viver do anarco-feminismo. IN:

Alfredo (org). Figuras de Foucault. Belo Horizonte: Autentica, 2006, p. $\overline{65-175}$.

\& VEIGA-NETO,

SCHIENBINGER, Londa. O feminismo mudou a ciência?. Tradução de Raul Fiker. Bauru: EDUSC, 2001.

SCHWARTZ, Juliana. A invasão dos ciborgues: A influência do ciberespaço nas representações de gênero dos adolescentes. Dissertação de Mestrado em Tecnologia - Programa de Pós-Graduação em Tecnologia, Universidade Tecnológica Federal do Paraná, 2005.

SCOTT, Joan. Gênero: uma categoria útil de análise histórica. IN: Educação e Realidade: Gênero e Educação. Porto Alegre V.16, n. 2, jul/dez, 1990.

SILVA, Tomaz Tadeu da. A produção social da identidade e da diferença. IN: (org).

Identidade e Ddiferença: a perspectiva dos estudos culturais. 4 ed. Petrópolis: Vozes, 2000, p. 73 102.

TOURAINE, Allan. Um novo paradigma: para compreender o mundo de hoje. 3 ed. Petrópolis: Vozes, 2007.

VARGAS, Milton. Para uma filosofia da tecnologia. São Paulo: Alfa-Omega, 1994.

VARGAS, Milton. Técnica, tecnologia e ciência. Revista Educação \& Tecnologia. Universidade Federal Tecnologia do Paraná: Curitiba, Vol. 6, Mai 2003.

VEIGA-NETO, Alfredo. Dominação, violência poder e educação escolar em tempos de império. IN: RAGO, Margareth \& (org). Figuras de Foucault. Belo Horizonte: Autentica, 2006, p. 13-38. 